\title{
Low Back Pain: Current Surgical Approaches
}

\author{
Santosh Baliga, Katrina Treon, Niall John Angus Craig \\ Department of Elective Orthopaedics, Woodend Hospital, Aberdeen, UK
}

Low back pain (LBP) is a worldwide phenomenon. The UK studies place LBP as the largest single cause of absence from work; up to $80 \%$ of the population will experience LBP at least once in their lifetime. Most individuals do not seek medical care and are not disabled by their pain once it is managed by nonoperative measures. However, around $10 \%$ of patients go on to develop chronic pain. This review outlines the basics of the traditional approach to spinal surgery for chronic LBP secondary to osteoarthritis of the lumbar spine as well as explains the novel concepts and terminology of back pain surgery. Traditionally, the stepwise approach to surgery starts with local anaesthetic and steroid injection followed by spinal fusion. Fusion aims to alleviate pain by preventing movement between affected spinal segments; this commonly involves open surgery, which requires large soft tissue dissection and there is a possibility of blood loss and prolonged recovery time. Established minimally invasive spine surgery techniques (MISS) aim to reduce all of these complications and they include laparoscopic anterior lumbar interbody fusion and MISS posterior instrumentation with pedicle screws and rods. Newer MISS techniques include extreme lateral interbody fusion and axial interbody fusion. The main problem of fusion is the disruption of the biomechanics of the rest of the spine; leading to adjacent level disease. Theoretically, this can be prevented by performing motion-preserving surgeries such as total disc replacement, facet arthroplasty, and non fusion stabilisation. We outline the basic concepts of the procedures mentioned above as well as explore some of the novel surgical therapies available for chronic LBP.

Keywords: Low back pain; Spinal fusion; Minimally invasive surgical procedures; Pedicle screws, Zygapophyseal joints; Intervertebral disc degeneration

\section{Introduction}

Low back pain (LBP) is a worldwide phenomenon. In the USA, back pain is the most common cause of activity limitation in people younger than 45 years, the second most frequent reason for visits to the family doctor, the fifth-ranking cause of admission to hospital, and the third most common cause of surgical procedures [1-3]. The UK studies place LBP as the largest single cause of absence from work, being responsible for about $12.5 \%$ of all sick days [4].

It is estimated that $75 \%$ to $80 \%$ of the adult population will experience LBP at least once in their lifetime [5-9]. Most of these individuals do not seek medical care and are not disabled by their pain; instead, they recover spontaneously after a short period of time. However, around $10 \%$ of these patients go on to develop chronic persistent or recurrent pain $[6,10,11]$.

There are many parameters mentioned in the literature characterizing the symptoms of chronic LBP (CLBP); thus, it is very difficult to categorise these patients when reviewing the literature and formulating a management plan [12].

One good definition of CLBP is lumbar, sacral, or lum-

Received Nov 27, 2014; Accepted Dec 3, 2014

Corresponding author: Santosh Baliga

Department of Elective Orthopaedics, Woodend Hospital, Aberdeen, Scotland, UK

Tel: +44-1224-552908, Fax: +44 1224 55100, E-mail: santoshbaliga@doctors.org.uk 
Table 1. Summary of the most common causes of lumbar back pain

\begin{tabular}{|c|c|}
\hline Cause & Description \\
\hline Discogenic back pain & $\begin{array}{l}\text { Pain from the innervated ligamentous layer of the annulus fibrosis when it is stretched with a bulging disc } \\
\text { Midline pain and worse with lordotic postures (bending and lifting) }\end{array}$ \\
\hline Radicular back pain & Pain extending to the buttock and or leg associated with disc herniation, spinal stenosis or intraspinal pathology \\
\hline Referred back pain & $\begin{array}{l}\text { Aortic aneurysm } \\
\text { Visceral (peptic ulcer, endometriosis, gallbladder disease, lung disease) } \\
\text { Infection } \\
\text { Urinary tract infection } \\
\text { Hip arthritis }\end{array}$ \\
\hline Spinal pathology & $\begin{array}{l}\text { Spinal infection } \\
\text { Spinal tumour } \\
\text { Spinal fracture }\end{array}$ \\
\hline Psychogenic back pain & $\begin{array}{l}\text { Must exclude organic pathology } \\
\text { A diagnosis of exclusion }\end{array}$ \\
\hline
\end{tabular}

bosacral spinal pain that is continuous for 12 weeks or essentially continuous due to low-level pain punctuated by exacerbations of pain, each of which is characterized as acute $[13,14]$.

This review outlines the basics of the traditional approach to spinal surgery for CLBP secondary to degenerative disc disease (DDD) and osteoarthritis of the lumbar spine as well as explains the novel concepts and terminology of back pain surgery.

\section{Aetiology}

The most important causes of back pain can be classified into four main types as summarised in Table 1.

A thorough history and physical examination are important to evaluate all possible factors contributing to the patient's pain and to assess its impact on the patient's functional ability [8]. The goal of medical evaluation is to efficiently identify the rare, serious causes (neoplasia, infection, inflammatory arthritis, and fracture) of LBP and to identify patients who may be at risk of delayed improvement due to neurologic impairment or psychosocial factors [10].

In patients without radicular symptoms or any red flags (e.g., inflammatory arthritis, infection, fracture, cancer, and cauda equina syndrome), a focused physical examination is usually sufficient [7]. In patients suspected of having a systemic or visceral cause of LBP, the physical examination must be expanded to include all organ systems [7].
- Red flags for back pain

- Saddle anaesthesia or paraesthesia

- Sudden and unexpected bladder or bowel dysfunction/ incontinence

- Unexpected laxity of the anal sphincter

- Severe or progressive lower limb neurological deficit

- Major trauma such as a road accident or fall from a height

- History of cancer

- Constitutional symptoms fever or chills

- Unexplained weight loss

- Immunocompromised patients

- Night pain that disturbs sleep

- Loss of tendon reflexes

- Up-going plantar reflex

Once other causes of back pain have been excluded and magnetic resonance imaging (MRI) scan (the gold standard investigation in back pain) confirms the presence of degenerated intervertebral discs, pain can be attributed to DDD. This is also known as discogenic back pain.

Disc degeneration, although in many cases asymptomatic, is strongly associated with back pain [15], Other clinical features of disc degeneration include disc herniation or prolapse. This is the main cause of sciatica and radicular pain (leg pain due to irritation of a nerve root in the spine) [16].

Discs degenerate far earlier than other musculoskeletal tissues; the first unequivocal findings of degeneration in the lumbar discs are seen in the age group 11 to 16 years 
[17]. About 20\% of people in their teens have discs with mild signs of degeneration; degeneration increases steeply with age, particularly in males, so that around $10 \%$ of 50 -year-old discs and $60 \%$ of 70 -year-old discs are severely degenerated [18].

In general terms, DDD alters disc height and the mechanics of the spinal column; adversely affecting the behaviour of other spinal structures such as muscles and ligaments (Fig. 1). In the long-term, it can lead to spinal stenosis, a major cause of pain and disability in the elderly. Its incidence is rising exponentially with current demographic changes and an increased aged population.

Spinal stenosis occurs when the space around the spinal cord narrows. This puts pressure on the spinal cord and nerve roots, leading to radicular pain, paraesthesia and or weakness.

The diagnosis of psychogenic back pain can only be made once all organic causes of pain have been excluded. This includes both pathology in the spine itself and elsewhere (such as the abdomen or chest) that can cause referred pain in the back. A classic example of this is pancreatic pathology that is often felt as back pain.

\section{The Treatment Ladder}

In patients with chronic pain, complete eradication of pain is rarely achieved and is not the goal of most interventions. Rather, the goals of treatment, which often require an interdisciplinary program, are moderation of pain, increased function, and decreased healthcare utilisa- tion [19].

Nonpharmacologic therapies, as part of an interdisciplinary program for chronic LBP can include physical modalities, exercise, education, transcutaneous electrical nerve stimulation, acupuncture, manipulation and injections. These are usually utilised as adjunctive therapies and do not necessarily substitute for pharmacotherapy [20]. Many programs also include cognitive-behavioural therapy. The majority of patients achieve satisfactory results from these conservative measures; needing no further invasive therapies.

Once conservative measures have failed and the patient continues to have life limiting back pain, surgical options are explored. A stepwise model with increasing use of invasive treatments is proposed below and it can be effective in the management of selected patients. The classic treatment ladder showed a large difference in terms of tissue dissection and length of recovery between simple discectomies and fusion procedures. Newer therapies including arthroplasty, non fusion stabilisation, and interspinous implants provide intermediate options as will be discussed (Fig. 2) [21].

\section{Who Should See a Spinal Surgeon?}

Patients with red flag symptoms should be referred on an urgent basis. In addition, we feel that patients who have failed conservative management and have had persistent pain for more than 6 months or individuals with chronic back pain with significant (new) radicular symptoms

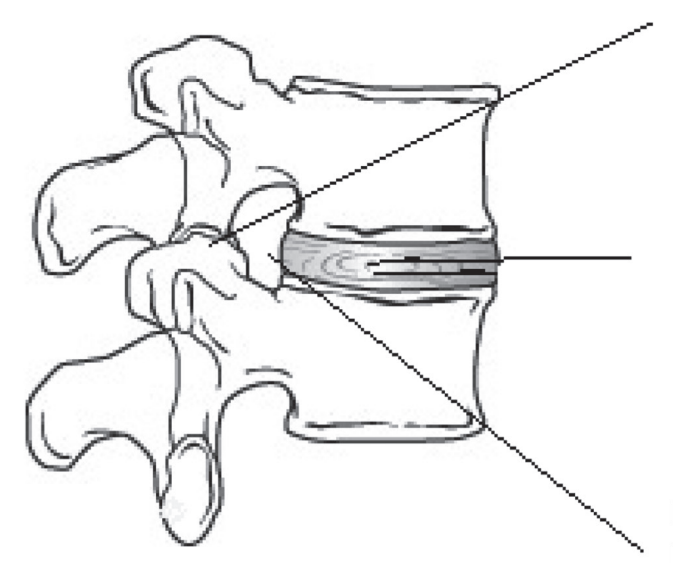

Narrowed nerve root foramen

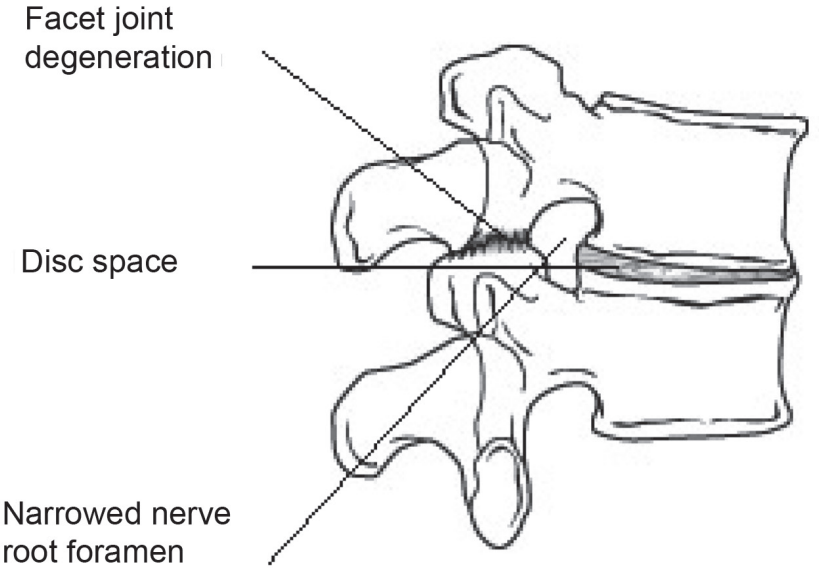

Fig. 1. In the normal spine, the discs have high water content (left). As the disc degenerates, it dehydrates, losing height or collapse (right). This puts pressure on the facet joints and may result in arthritis of these joints. Both diagrams show a spinal segment; two adjacent vertebrae with a pair of facet joints and the intervertebral disc. 

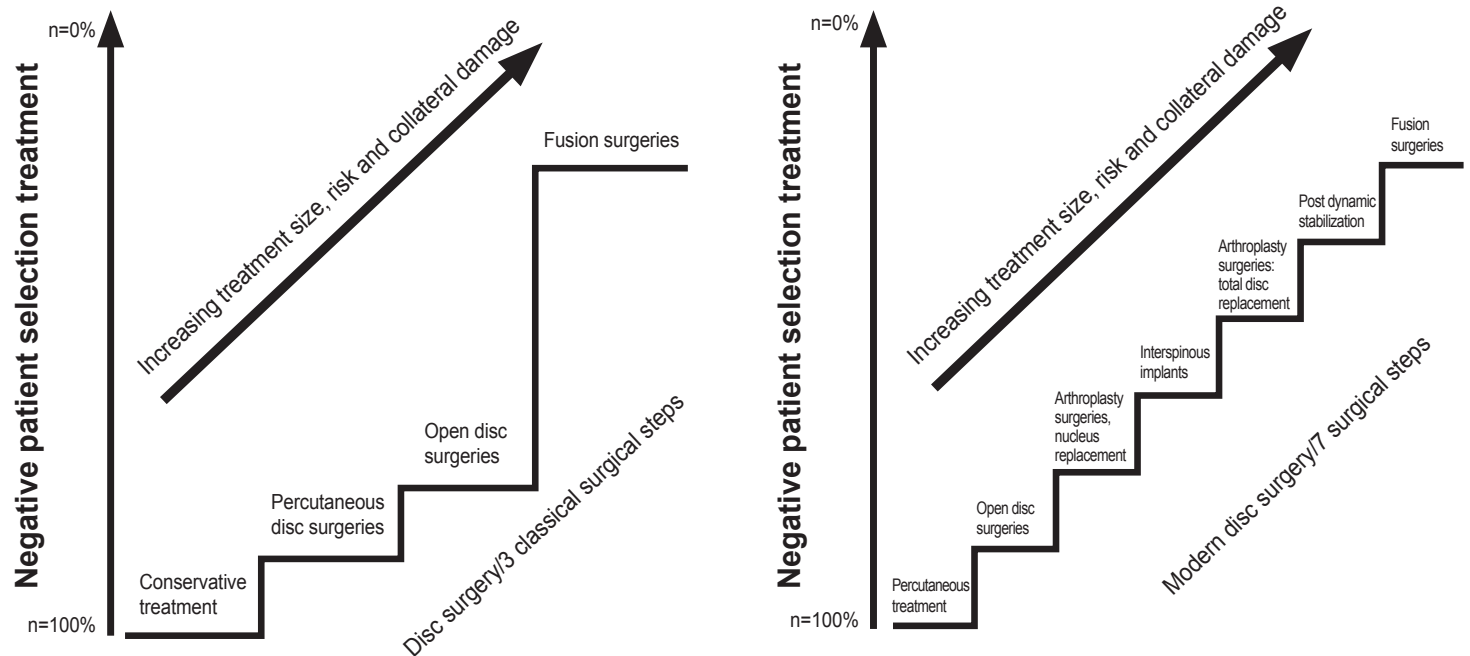

Fig. 2. The classic versus new treatment ladder of back pain. Reprinted from Bertagnoli [21] with permission from North American Spine Society.

should be considered for referral to a spinal surgeon on a routine basis.

- Indications for referral to a spinal surgeon

- Red flags

- Back pain persisting for 6 months despite conservative treatment

- Persistent radicular/leg pain ( $>3$ months)

\section{Surgical Options for Back Pain}

\section{Injection therapy}

When a full regimen of pharmacological analgesia and physiotherapy has failed to control the symptoms, injection therapy is usually the first line of invasive management offered to the patient. A needle is used to deliver a local anaesthetic and steroid into and around the painful joint. This temporarily suppresses the local inflammatory process thereby reducing pain levels. Injections can be performed into the facet joints, into the epidural space via the caudal/sacral route or around the nerve root. The latter two options are primarily aimed at neurological/radicular pain and symptoms, secondary to spinal and nerve root canal stenosis; facet joint injections are targeted at back pain.

Injection therapy is generally used as a temporary measure, but it can be very useful in the management of acute exacerbations of back pain. It gives the patient a 'time window' with significant improvements in pain levels during which the patient is encouraged to see a physiotherapist and to participate in an intensive, self-directed, and progressive exercise programme. Unfortunately, not all patients respond to injection therapy, and as a general rule, as the degenerative process progresses, the time window shortens.

The decision making process regarding the site, level, and type of injection therapy varies greatly depending on the patient's symptoms and site of pathology. Sometimes individuals who have failed to respond to one type of injection benefit from injections at a different site. However, we feel that if a patient has not experienced at least six weeks of significant relief of symptoms from one injection, the risks of cumulative steroid dose outweigh the benefits of repeat injection. The cumulative steroid dose also influences the number of injections per time period. Although it is important to assess this on a case by case basis, we try to avoid patients receiving injection therapy more than three times a year, with each therapy constituting 40 to $80 \mathrm{mg}$ of triamcinolone.

- Key points of injection therapy

- Temporary measure to treat acute flare-up of pain

- Can initially worsen symptoms in the first 48 hours prior to the steroid component becoming effective

- Patient can return to work as soon as they feel able to 


\section{Non fusion stabilisation}

This has been an evolving technology over the last 15 to 20 years and offers a potential alternative to traditional fusion. Many different systems exist, but essentially they all aim to use flexible materials to stabilise the spine. The first design was called the Graf ligament; the implants employed screws to attach an artificial 'ligament' to the spine. It was designed to limit flexion and less so extension of a specific spinal segment by locking the facet joints. Results from early studies were very promising with one paper showing Graf ligament stabilisation resulting in a higher satisfaction rate (93\%) when compared to traditional fusion (78\%) [22]. However, on a longer follow-up, the use of the Graf ligament was found to be associated with high revision rates with up to $41 \%$ of patients stating they would not have the operation again $[23,24]$.

Dynesys is a similar type of device that has several modifications from the original Graf ligament: it limits both flexion and extension and hence helps to unload the intervertebral disc. Problems associated with these devices include screw loosening and cut out in the osteopenic bone; hence, it is used with caution in the elderly and those with osteoporotic bone. Initial studies found that Dynesys was preferable to fusion for treatment of degenerative spondylolisthesis and stenosis [25]. However, results of longer term studies were less encouraging, showing that patients undergoing Dynesys stabilisation had a $28 \%$ chance of requiring revision surgery [26,27]. Another study suggested that disc degeneration at the bridged and adjacent segments appears to continue despite Dynesys stabilisation [28]. More recent reports state that Dynesys stabilisation appears to be acceptable compared to fusion [29-31].

Another approach to non fusion spinal stabilisation has been the use of interspinous stabilisation devices. These fill the interspinous space and are attached to the spine by bands or sutures. They act by limiting flexion and extension and are often used in mild segmental degeneration or instability after open spinal decompression. These stabilisation devices include the Wallis ligament, DIAM, and Coflex. These devices increase the stability of a spinal segment and can be used in an early stage of DDD when at least $50 \%$ of disc height is maintained or in situations when DDD is likely to progress significantly; post discectomy with massive herniations, recurrent discectomies or adjacent segment degeneration after fusion [32]. Unfortunately, studies have suggested that the Wallis Ligament cannot reliably prevent recurrent disc herniation [33]. The number of good quality randomised trials is low, and there are many recommendations for further studies [34].

Similarly, DIAM has shown promising results for back pain due to disc degeneration with improved pain in $78.9 \%$ of the cases for up to 4 years [35-38]. The first prospective controlled study comparing decompression with Coflex to decompression alone suggested that results in both groups are similar $[39,40]$.

The advantages of interspinous devices are that they have lower risk than pedicle screws (which can penetrate neural elements of the cord/cauda equina). Most studies concluded that the results are similar to those of fusion and decompression although they can work very well in selected cases (Fig. 3).

1) Total disc arthroplasty

Traditionally, the mainstay of surgical management of back pain has been fusion. However, fusion of a spinal segment may have detrimental effects on the normal physiological and biomechanical function of the rest of the spine [41]. Decreased segmental mobility could lead to increased stress on the neighbouring spine, which increases degeneration at these levels. This is known as 'adjacent level disease' $[42,43]$. For this reason non fusion/ motion preserving techniques have been developed.

- Key points of non fusion stabilisation

- Various devices are used to prevent further disc degeneration

- Unpredictable efficacy; some patients achieve much better results than others

- Average hospital stay of 2 to 4 days

- Patients must avoid heavy lifting for at least 6 weeks; but can return to desk based activities once the wound has healed

Total disc replacement (TDR) is one such technique and it was developed to avoid the problems of adjacent level disease by preserving motion at the level. Pain relief is thought to be due to a combination of excision of the painful disc and restoration or improvement of load transfer [44,45]. Prostheses are mainly used in the 
treatment of early disc degeneration, prior to facet joint degeneration. The prosthesis is implanted via an anterior retroperitoneal approach. After complete discectomy, the disc space is prepared and the implant is tapped into place (Fig. 4).

Trials of disc replacement indicate a lower morbidity, quicker recovery, and better clinical outcome in these patients at one year compared to fusion surgery. However, at two years, there is a less significant difference between the two groups $[46,47]$. In vitro studies indicate reduction of degeneration of the adjacent spine, but this still needs to be evaluated in prospective long-term studies.

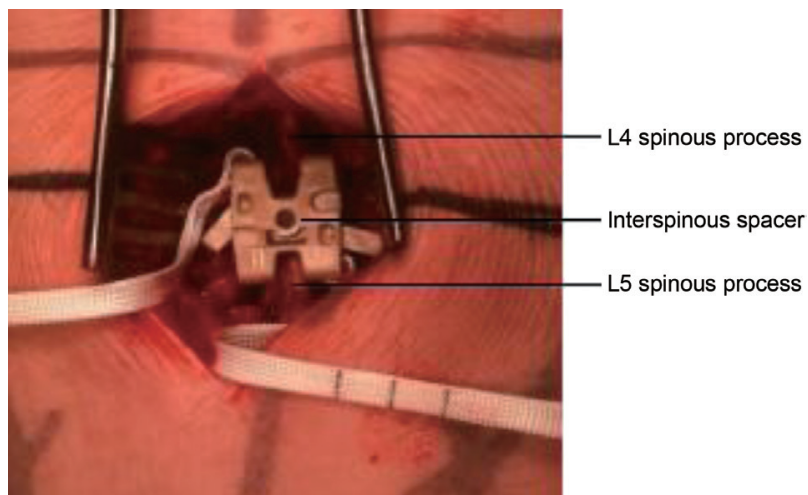

Fig. 3. A picture of interspinous spacer (SMS 0 Spine) implanted between the spinous process of two lumbar vertebrae.
- Key points of TDR

- Allows movement to be preserved at the 'degenerated/arthritic' level

- May prevent 'adjacent segment disease', i.e., arthritis developing at the vertebral joint above

- Needs large exposure to front of the spine, and hence longer recovery and potentially higher risk of complications

- Hospital stay between 4 to 7 days

- Patients will need to be at least 6 weeks away from work, and they will need to avoid prolonged sitting and heavy lifting

2) Facet arthroplasty/facet replacement

Total facet arthroplasty (TFA) is an articulating joint prosthesis intended to restore normal motion and provide stabilisation of spinal segments through replacement of the facets and excised elements of the posterior lumbar spine following facetectomy (removal of the facet joints) and neural decompressive procedures. Implanted via an open posterior surgical approach, the prosthesis is fixed into the pedicles using bone cement and is intended to provide immediate alignment and stabilisation of the spinal segment, while maintaining motion (Fig. 5) [48].

In vitro biomechanical testing of one type of the TFA has shown that the kinematics of the spine is more akin to
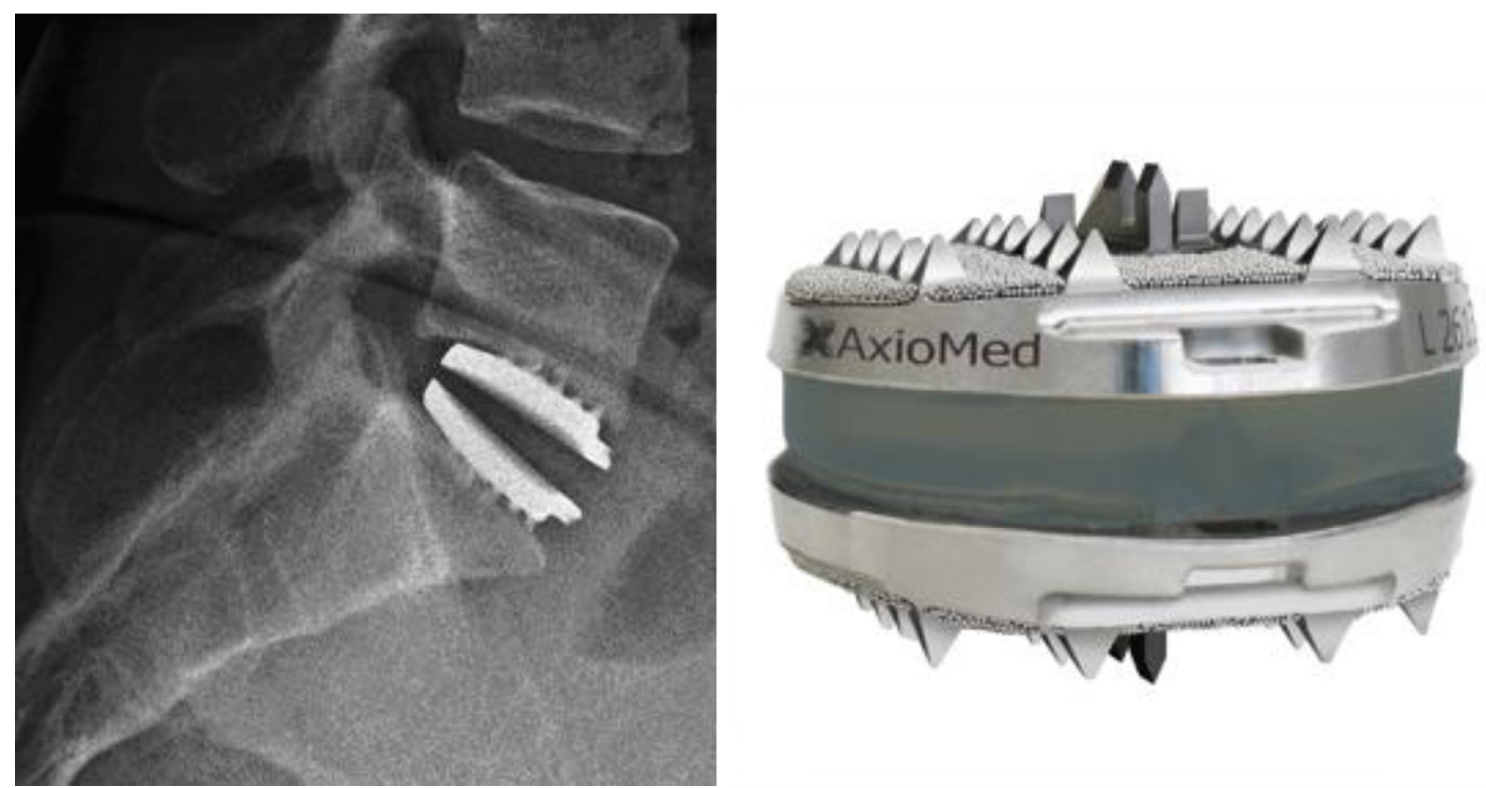

Fig. 4. Radiographs of an L5-S1 total disc replacement and a photograph of the prosthesis. Reprinted image of the Freedom Lumbar Disc with permission from AxioMed Spine Co., Cleveland, OH, USA. 
the intact spine than that of posterior fusion [49]. However, this technology is still in the embryonic stage; as yet no clinical outcome studies exist and no case reports of fatigue of the implant have been reported [49].

Lessons learnt from the development of other joint replacement techniques lead us to hypothesise that the variation in alignment and hence in biomechanical kinematics between individuals and even between spinal levels has to be appreciated to ensure the success of this technology.

- Key points of total facet arthroplasty (TFA)

- For the treatment of symptomatic 'facet joint arthritis'

- A relatively novel procedure; long-term results unknown

- Allows movement to be preserved

- Not widely performed

\section{3) Fusion}

Lumbar fusion is often used in the treatment of symptomatic lumbar DDD when conservative management has failed [50]. Results of lumbar fusion include 50\% reduction in back and leg pain intensities as well as improvement in patient outcome scores and mental and physical Short Form-36 scores [51].

The logic behind surgery is that by fusing two vertebrae together, they will act and function as a solid bone. Since lumbar pain may be caused by excessive motion of the vertebra, the goal of spinal fusion surgery is to eliminate that

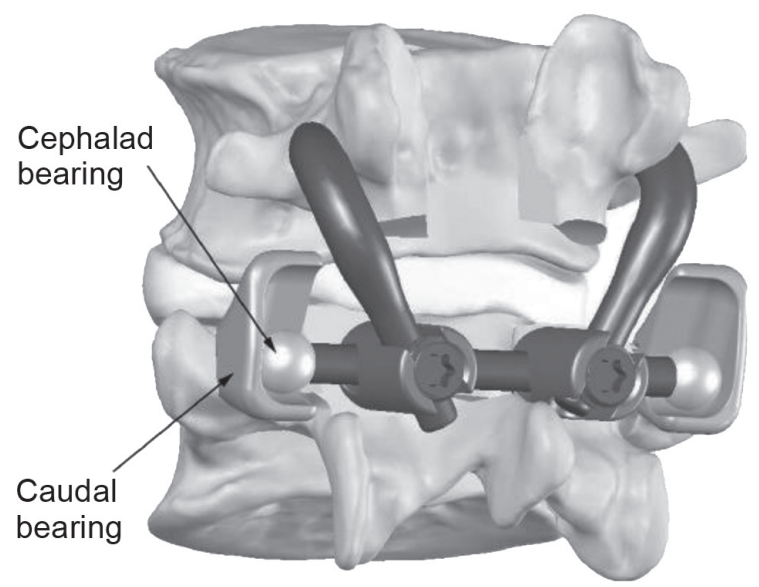

Fig. 5. Schematic diagram of the total facet arthroplasty system. Reprinted with permission from Globus Medical Inc., Phoenixville, PA, USA. extra motion in between the vertebrae, alleviating pain.

A variety of techniques have been developed for lumbar spinal fusion. Interbody fusion has become widely popular since it provides a large surface area for fusion with the graft under compression. Traditionally, this can be achieved via either anterior or posterior approaches. Anterior surgery or anterior lumbar interbody fusion (ALIF) involves access to the lumbar spine via the abdominal cavity, and hence it carries the risk of catastrophic bleeding from injury to major vessels as well as iatrogenic injury to viscera and associated structures. The posterior approach, posterior lumbar interbody fusion (PLIF) is more commonly used, as the associated spinal canal stenosis can also be addressed by canal decompression (Fig. 6).

Another commonly used fusion technique, either in combination with PLIF or alone is posterolateral fusion. In this technique, a fusion mass is made using a bone graft between the transverse processes of adjacent vertebrae. This technique is supplemented with instrumentation, typically in the form of pedicle screws and rods to stabilise the segment; allowing fusion to occur between the two vertebrae (Fig. 7).

No particular technique has yet been demonstrated to yield superior results [52], and hence the technique used is dependent on patient size and anatomy, deformity of the spine, and surgeon's preference.

- Key points of fusion

- Gold standard surgical treatment in the management of back pain

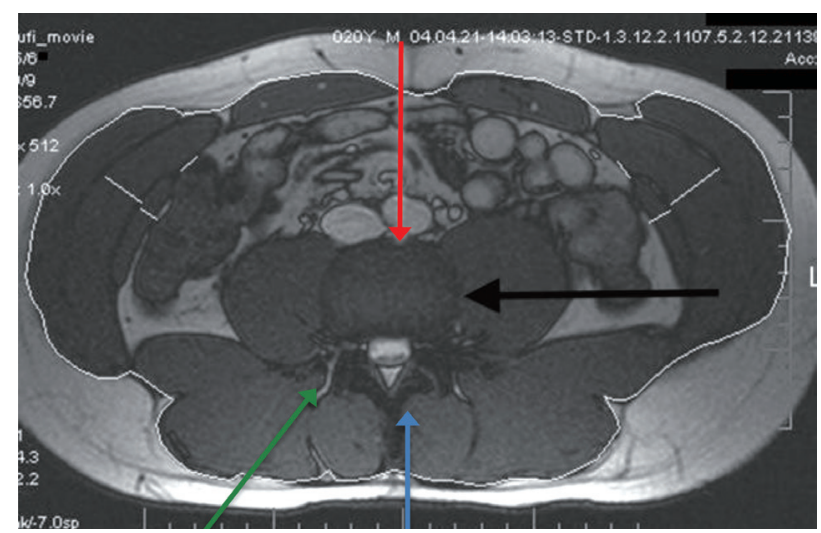

Fig. 6. Approaches to lumbar spine can be broadly divided into anterior (red arrow) and posterior (blue arrow). Axial magnetic resonance imaging also demonstrating extreme lateral access (black arrow) and transforaminal (green arrow) approaches. 
- Many different techniques and approaches; all aim to fuse arthritic/painful joint

- Hospital stay of 37 days

- Can initially worsen pain in the first 6 weeks

- No heavy lifting for 3 months, until bony fusion has occurred. This may be delayed in smokers

- Patient can return to desk based activities after 2 weeks or once pain reduces

\section{4) Minimally invasive fusion}

Open surgical approaches to fusion such as ALIF and PLIF are complex and often require muscular and ligamentous dissection, neural retraction, and mobilisation of vascular and visceral structures. Complications include vascular injury, sympathetic dysfunction, and bowel injuries [53]. Advances in minimally invasive spine surgery (MISS) have led to a number of alternative approaches, all designed to minimise morbidity and the complications associated with a traditional anterior surgical approach.

Established minimally invasive techniques include laparoscopic ALIF, minimally invasive PLIF, and these have been discussed extensively in the literature [54-56].

More recent developments in MISS include the extreme lateral interbody fusion (XLIF) approaches, as well as transsacral fusion (axial lumbar interbody fusion, AxiaLIF). Less soft tissue dissection allows for early recovery and rehabilitation of the patient. It leads to less postoperative pain, reduced surgical time, and less blood loss $[57,58]$. For the patient, this means less time in the hospi-

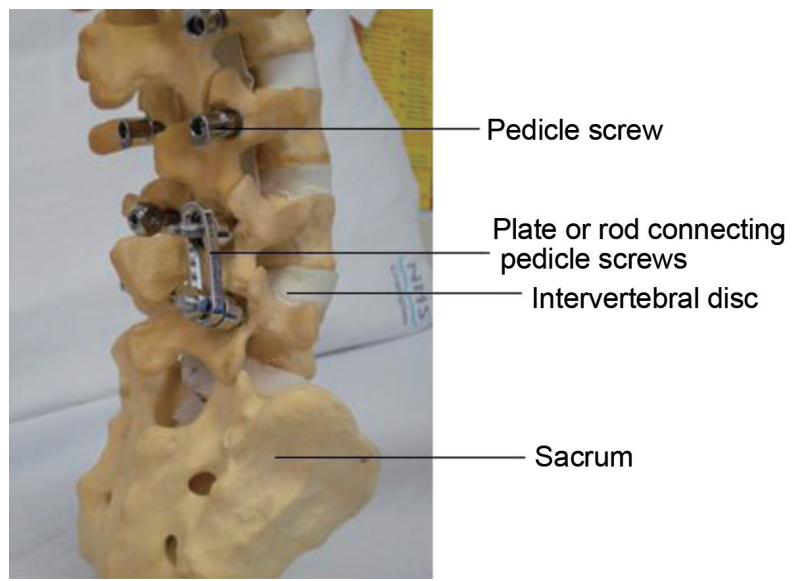

Fig. 7. Pedicle screws are inserted posteriorly through the pedicles into the vertebral body. Rods are used to stabilise the two vertebrae by linking them to the pedicle screws. If indicated, several levels can be fused at the same time. tal and a faster return to daily activities.

\section{Extreme Lateral Interbody Fusion}

This technique can be used to gain access to the lumbar spine via a lateral approach that passes through the retroperitoneal fat and psoas major muscle. Hence, the potential complications with an anterior transperitoneal approach to the lumbar spine can be avoided and major vessels are not encountered, the procedure can be done through two 3 to $4-\mathrm{cm}$ incisions [53].

The XLIF approach allows for anterior access to the disc space without the complications of an anterior intraabdominal procedure (Fig. 8).

Published results of this technique are encouraging, $95 \%$ fusion rates at 6 months; $86.7 \%$ of patients reported satisfaction with their procedures at 1 year, $90.4 \%$ of patients electing to have the surgery again if needed. Compared with traditional open approaches, the XLIF technique has been shown to result in a lower incidence of infection, visceral and neurologic injury, and transfusion

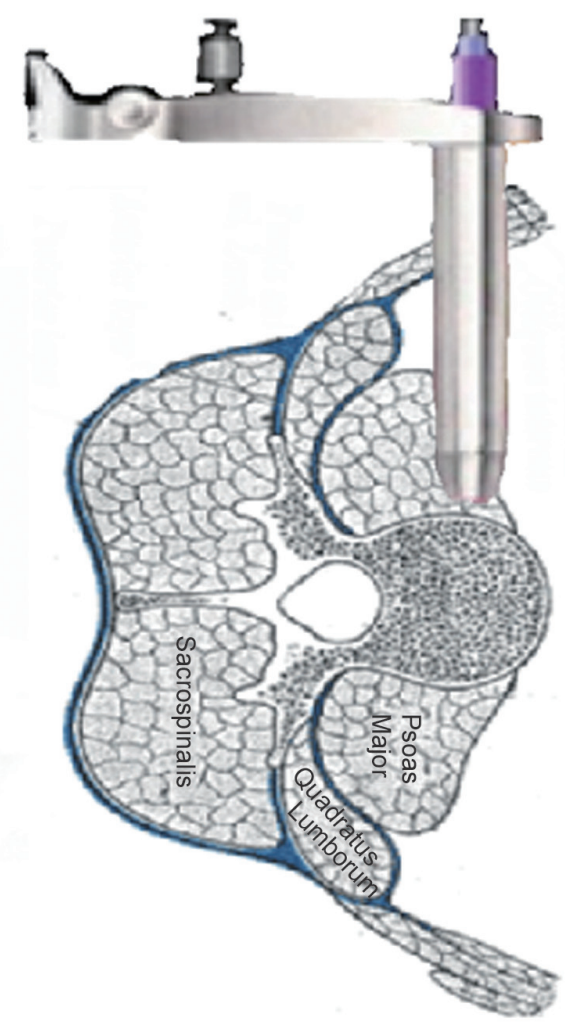

Fig. 8. Schematic drawing showing the extreme lateral interbody fusion procedure; the retractor is inserted into the retroperitoneal space, penetrating the psoas muscle, and positioned directly on the lateral intervertebral disc space. 
as well as markedly shorter hospitalization $[59,60]$.

There are several limitations to the XLIF approach. Access to the L5-S1 disc is not possible and the L4-5 disc level can be obstructed by a high iliac crest or aberrant lumbar plexus anatomy. Similarly, access to the L1-2 level can sometimes be hindered by lower ribs. Trauma to the lumbar plexus is a potentially disastrous complication that can occur if adequate caution is not exercised while dissecting through the psoas muscle. However, intraoperative neural monitoring is designed to detect the lumbar plexus at a safe distance before significant retraction and insertion of surgical instruments (Fig. 9) [59].

\section{Axial Lumbar Interbody Fusion}

The AxiaLIF system (TranS1 Inc., Wilmington, NC, USA) is based on the application of minimally invasive tech-

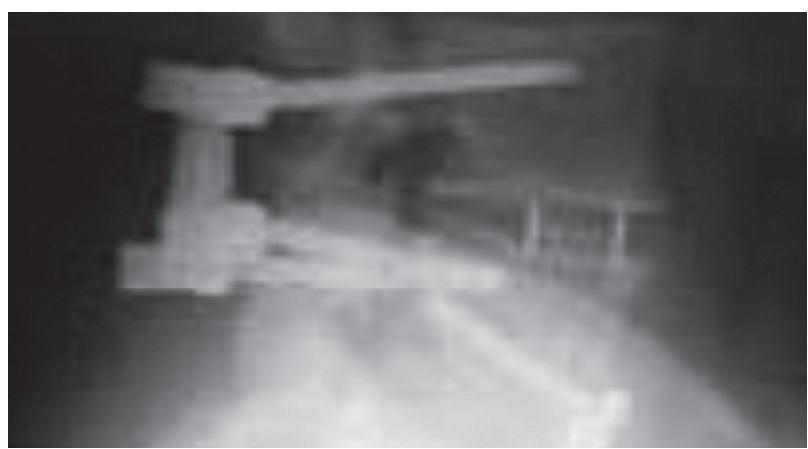

Fig. 9. Radiograph showing interbody fusion after the extreme lateral interbody fusion procedure supplemented by posterior instrumentation, which can also be achieved by minimally invasive spine surgery; useful in correcting the spinal deformity. niques to attain fusion at L5-S1 and L4-S1 levels utilising an axially placed lumbar device implanted via the presacral retroperitoneal tract. The presacral access route to the L5-S1 intervertebral space is a distinct surgical approach to lumbar interbody fusion. This atraumatic tissue plane alleviates the need for the surgeon to cut through paraspinal muscles and remove laminae and facet joints, potentially lessening postoperative patient pain and the likelihood of complications.

Biomechanical studies show the AxiaLIF rod provides more stability when compared with all other stand-alone interbody cages (Figs. 10, 11) [61].

Published case series of this technique show mean pain scores of over $60 \%$. Two-year clinical success rates on the basis of change of at least $30 \%$ relative to baseline were $86 \%$ for pain and $74 \%$ for function. The overall radiographic fusion rate at 2 years was $94 \%$ [62].

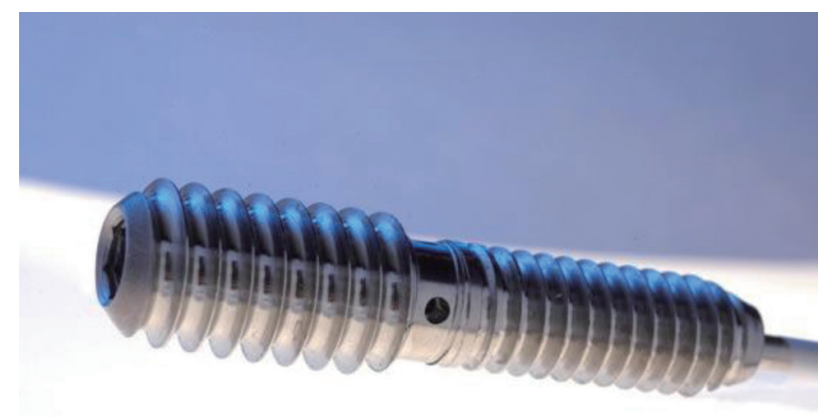

Fig. 10. The axial interbody fusion rod is implanted into the L5-S1 disc space, making it a stable construct containing bone graft. Reprinted with permission from Surgi-C Ltd., Birmingham, UK.
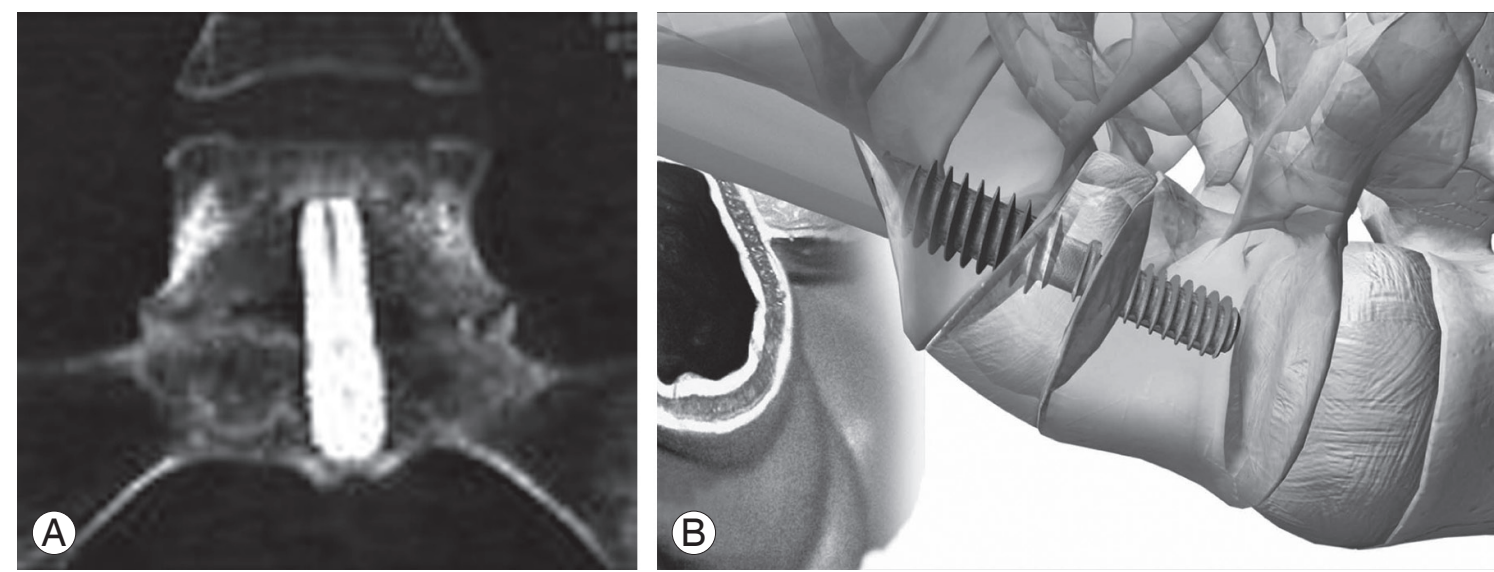

Fig. 11. (A) Computer tomography image of the axial interbody fusion with the formation of a bridging callus between the sacrum and the L5 vertebra. (B) Schematic showing AxiaLIF Rod inserted between S1 and L5 vertebrae. Reprinted from Tobler et al. [62] with permission of Wolters Kluwer Health Inc. 
The primary concern about AxiaLIF is safety; anatomic studies show a great variation in the anatomy increasing the chance of pelvic splanchnic nerve and lateral sacral vessel injury as well as rectal perforation [63].

In addition to this, revision surgery for pseudarthrosis (failure of fusion) with the AxiaLIF system poses a challenge. Traversing an already scarred presacral tract raises concerns of the previously mentioned complications [64].

- Key points of minimally invasive fusion (MISS)

- Many different techniques for performing MISS exist; AxiaLIF and XLIF are two options that are in widespread use

- All techniques aim to achieve fusion through small incisions and hence less soft tissue damage

- This translates into less postoperative pain, quicker mobilisation, and shorter hospital stay (2-4 days)

- No heavy lifting for 3 months, until bony fusion has occurred. This may be delayed in smokers

- Patient can return to desk based activities after 2 weeks or once pain reduces

\section{Conclusions}

Chronic lumbar back pain is common, and the majority of patients can be successfully managed by a combination of conservative approaches. A significant number of patients continue to have life limiting CLBP despite conservative measures. Once other causes of back pain have been ruled out by rigorous history, examination, and directed investigations, in most cases, CLBP can be attributed to DDD.

Traditionally, the stepwise approach to surgery starts with local and steroid injection leading to fusion. Fusion aims to alleviate pain by preventing movement between the two affected vertebrae. A fusion mass can be created between the transverse process in the 'posterolateral gutter' during posterior surgery or between vertebral bodies in the form of ALIF or PLIF.

Established MISS techniques include laparoscopic ALIF and MISS posterior instrumentation with pedicle screws and rods. Newer MISS techniques include XLIF and AxiaLIF. All of these techniques aim to reduce tissue dissection, blood loss and recovery time; however, they are heavily dependent on the X-ray and have their own set of complications.
No particular technique has yet been demonstrated to yield superior results [52], and hence the technique used is dependent on patient size and anatomy, deformity of the spine, and surgeon's preference.

The main problem of fusion is the disruption of the biomechanics and kinematics of the rest of the spine caused by a rigid segment; leading to adjacent level disease. Theoretically, this can be prevented by performing motion preserving surgeries such as TDR, facet arthroplasty, and non fusion stabilisation. However, this is yet to be demonstrated by adequate clinical data.

Pioneering research into the treatment of CLBP in the future involves a better understanding of disc physiology, pathology, and stem cell research into regeneration of human disc tissue. Disc cells have been grown in vitro; however, the translation of this research into clinical practice is probably still several years away [65].

In addition to this, there is particular interest in understanding of the way in which chronic pain is controlled and modulated. Functional MRI studies have shown that some patients can modulate chronic pain in a 'central' manner. In clinical practice, this means that despite elimination of peripheral pain sources, hard-wired central pathways can cause residual pain leading to unsuccessful surgery. This phenomenon is not confined to the spine, and it has been found to be the cause of failed hip and knee replacement as well as failed back surgery. It is hoped that a better understanding of who develops central pain pathways and when they develop these pathways will allow early intervention to prevent this phenomenon [66].

\section{Conflict of Interest}

No potential conflict of interest relevant to this article was reported.

\section{References}

1. Praemer A, Furner S, Rice DP; American Academy of Orthopaedic Surgeons. Musculoskeletal conditions in the United States. Park Ridge: American Academy of Orthopaedic Surgeons; 1992.

2. Taylor VM, Deyo RA, Cherkin DC, Kreuter W. Low back pain hospitalization. Recent United States trends and regional variations. Spine (Phila Pa 1976) 1994; 19:1207-12. 
3. Hart LG, Deyo RA, Cherkin DC. Physician office visits for low back pain: frequency, clinical evaluation, and treatment patterns from a U.S. national survey. Spine (Phila Pa 1976) 1995;20:11-9.

4. Frank A. Low back pain. BMJ 1993;306:901-9.

5. Andersson GB. Epidemiology of low back pain. Acta Orthop Scand Suppl 1998;281:28-31.

6. Dillingham T. Evaluation and management of low back pain: an overview. State Art Rev 1995;9:559-74.

7. Frymoyer JW. Back pain and sciatica. N Engl J Med 1988;318:291-300.

8. McKenzie R, May S. The lumbar spine: mechanical diagnosis and therapy. Wellington: Spinal Publications; 2003.

9. Woolf AD, Pfleger B. Burden of major musculoskeletal conditions. Bull World Health Organ 2003;81:64656.

10. Breivik H, Collett B, Ventafridda V, Cohen R, Gallacher D. Survey of chronic pain in Europe: prevalence, impact on daily life, and treatment. Eur J Pain 2006;10:287-333.

11. Lawrence RC, Helmick CG, Arnett FC, et al. Estimates of the prevalence of arthritis and selected musculoskeletal disorders in the United States. Arthritis Rheum 1998;41:778-99.

12. Malliou P, Gioftsidou A, Beneka A, Godolias G. Measurements and evaluations in low back pain patients. Scand J Med Sci Sports 2006;16:219-30.

13. Croft PR, Macfarlane GJ, Papageorgiou AC, Thomas E, Silman AJ. Outcome of low back pain in general practice: a prospective study. Bmj 1998;316:1356-9.

14. Scientific approach to the assessment and management of activity-related spinal disorders: a monograph for clinicians: report of the Quebec Task Force on Spinal Disorders. Spine (Phila Pa 1976) 1987;12(7 Suppl):S159.

15. Luoma K, Riihimaki H, Luukkonen R, Raininko R, Viikari-Juntura E, Lamminen A. Low back pain in relation to lumbar disc degeneration. Spine (Phila Pa 1976) 2000;25:487-92.

16. Boden SD, Davis DO, Dina TS, Patronas NJ, Wiesel SW. Abnormal magnetic-resonance scans of the lumbar spine in asymptomatic subjects: a prospective investigation. J Bone Joint Surg Am 1990;72:403-8.

17. Boos N, Weissbach S, Rohrbach H, Weiler C, Spratt KF, Nerlich AG. Classification of age-related changes in lumbar intervertebral discs: 2002 Volvo Award in basic science. Spine (Phila Pa 1976) 2002;27:2631-44.

18. Miller JA, Schmatz C, Schultz AB. Lumbar disc degeneration: correlation with age, sex, and spine level in 600 autopsy specimens. Spine (Phila Pa 1976) 1988; 13:173-8.

19. Sanders SH, Rucker KS, Anderson KO, et al. Clinical practice guidelines for chronic non-malignant pain syndrome patients. J Back Musculoskelet Rehabil 1995;5:115-20.

20. Owens MK, Ehrenreich D. Literature review of nonpharmacologic methods for the treatment of chronic pain. Holist Nurs Pract 1991;6:24-31.

21. Bertagnoli R. Disc surgery in motion. SpineLine 2004;5(Nov/Dec):23-8.

22. Madan S, Boeree NR. Outcome of the Graf ligamentoplasty procedure compared with anterior lumbar interbody fusion with the Hartshill horseshoe cage. Eur Spine J 2003;12:361-8.

23. Rigby MC, Selmon GP, Foy MA, Fogg AJ. Graf ligament stabilisation: mid- to long-term follow-up. Eur Spine J 2001;10:234-6.

24. Askar Z, Wardlaw D, Muthukumar T, Smith F, Kader D, Gibson S. Correlation between inter-vertebral disc morphology and the results in patients undergoing Graf ligament stabilisation. Eur Spine J 2004;13:7148.

25. Schwarzenbach O, Berlemann U, Stoll TM, Dubois G. Posterior dynamic stabilization systems: DYNESYS. Orthop Clin North Am 2005;36:363-72.

26. Bothmann M, Kast E, Boldt GJ, Oberle J. Dynesys fixation for lumbar spine degeneration. Neurosurg Rev 2008;31:189-96.

27. Beastall J, Karadimas E, Siddiqui M, et al. The Dynesys lumbar spinal stabilization system: a preliminary report on positional magnetic resonance imaging findings. Spine (Phila Pa 1976) 2007;32:685-90.

28. Kumar A, Beastall J, Hughes J, et al. Disc changes in the bridged and adjacent segments after Dynesys dynamic stabilization system after two years. Spine (Phila Pa 1976) 2008;33:2909-14.

29. Welch WC, Cheng BC, Awad TE, et al. Clinical outcomes of the Dynesys dynamic neutralization system: 1-year preliminary results. Neurosurg Focus 2007; 22:E8.

30. Yu SW, Yang SC, Ma CH, Wu CH, Yen CY, Tu YK. Comparison of Dynesys posterior stabilization and posterior lumbar interbody fusion for spinal stenosis 
L4L5. Acta Orthop Belg 2012;78:230-9.

31. Yu SW, Yen CY, Wu CH, Kao FC, Kao YH, Tu YK. Radiographic and clinical results of posterior dynamic stabilization for the treatment of multisegment degenerative disc disease with a minimum follow-up of 3 years. Arch Orthop Trauma Surg 2012;132:583-9.

32. Senegas J. Mechanical supplementation by non-rigid fixation in degenerative intervertebral lumbar segments: the Wallis system. Eur Spine J 2002;11 Suppl 2:S164-9.

33. Floman Y, Millgram MA, Smorgick Y, Rand N, Ashkenazi E. Failure of the Wallis interspinous implant to lower the incidence of recurrent lumbar disc herniations in patients undergoing primary disc excision. J Spinal Disord Tech 2007;20:337-41.

34. Korovessis P, Repantis T, Zacharatos S, Zafiropoulos A. Does Wallis implant reduce adjacent segment degeneration above lumbosacral instrumented fusion? Eur Spine J 2009;18:830-40.

35. Kabir SM, Gupta SR, Casey AT. Lumbar interspinous spacers: a systematic review of clinical and biomechanical evidence. Spine (Phila Pa 1976) 2010;35: E1499-506.

36. Buric J, Pulidori M, Sinan T, Mehraj S. DIAM device for low back pain in degenerative disc disease: 24 months follow-up. Acta Neurochir Suppl 2011;108: 177-82.

37. Fabrizi AP, Maina R, Schiabello L. Interspinous spacers in the treatment of degenerative lumbar spinal disease: our experience with DIAM and Aperius devices. Eur Spine J 2011;20 Suppl 1:S20-6.

38. Buric J, Pulidori M. Long-term reduction in pain and disability after surgery with the interspinous device for intervertebral assisted motion (DIAM) spinal stabilization system in patients with low back pain: 4-year follow-up from a longitudinal prospective case series. Eur Spine J 2011;20:1304-11.

39. Tsai KJ, Murakami H, Lowery GL, Hutton WC. A biomechanical evaluation of an interspinous device (Coflex) used to stabilize the lumbar spine. J Surg Orthop Adv 2006;15:167-72.

40. Richter A, Schutz C, Hauck M, Halm H. Does an interspinous device (Coflex) improve the outcome of decompressive surgery in lumbar spinal stenosis? One-year follow up of a prospective case control study of 60 patients. Eur Spine J 2010;19:283-9.

41. Gibson JN, Waddell G. Surgery for degenerative lum- bar spondylosis: updated Cochrane Review. Spine (Phila Pa 1976) 2005;30:2312-20.

42. Ghiselli G, Wang JC, Bhatia NN, Hsu WK, Dawson EG. Adjacent segment degeneration in the lumbar spine. J Bone Joint Surg Am 2004;86:1497-503.

43. Gillet P. The fate of the adjacent motion segments after lumbar fusion. J Spinal Disord Tech 2003;16:33845.

44. Bono CM, Garfin SR. History and evolution of disc replacement. Spine J 2004;4:145S-150S.

45. Le Huec J, Basso Y, Mathews H, et al. The effect of single-level, total disc arthroplasty on sagittal balance parameters: a prospective study. Eur Spine J 2005;14: 480-6.

46. Guyer RD, McAfee PC, Hochschuler SH, et al. Prospective randomized study of the Charite artificial disc: data from two investigational centers. Spine J 2004;4:252S-259S.

47. Berg S, Tullberg T, Branth B, Olerud C, Tropp H. Total disc replacement compared to lumbar fusion: a randomised controlled trial with 2-year follow-up. Eur Spine J 2009;18:1512-9.

48. Palmer DK, Inceoglu S, Cheng WK. Stem fracture after total facet replacement in the lumbar spine: a report of two cases and review of the literature. Spine J 2011;11:e15-9.

49. Zhu Q, Larson CR, Sjovold SG, et al. Biomechanical evaluation of the Total Facet Arthroplasty System: 3-dimensional kinematics. Spine (Phila Pa 1976) 2007; 32:55-62.

50. Murtagh RD, Quencer RM, Cohen DS, Yue JJ, Sklar EL. Normal and abnormal imaging findings in lumbar total disk replacement: devices and complications. Radiographics 2009;29:105-18.

51. Becker P, Bretschneider W, Tuschel A, Ogon M. Life quality after instrumented lumbar fusion in the elderly. Spine (Phila Pa 1976) 2010;35:1478-81.

52. Fritzell P, Hagg O, Wessberg P, Nordwall A. Chronic low back pain and fusion: a comparison of three surgical techniques: a prospective multicenter randomized study from the Swedish lumbar spine study group. Spine (Phila Pa 1976) 2002;27:1131-41.

53. Ozgur BM, Aryan HE, Pimenta L, Taylor WR. Extreme lateral interbody fusion (XLIF): a novel surgical technique for anterior lumbar interbody fusion. Spine J 2006;6:435-43.

54. Heim SE, Altimari A. Laparoscopic approaches to 
fusion of the lumbosacral spine: latest techniques. Orthop Clin North Am 2002;33:413-20.

55. Moskowitz A. Transforaminal lumbar interbody fusion. Orthop Clin North Am 2002;33:359-66.

56. Agazzi S, Reverdin A, May D. Posterior lumbar interbody fusion with cages: an independent review of 71 cases. J Neurosurg 1999;91:186-92.

57. Beringer WF, Mobasser JP. Unilateral pedicle screw instrumentation for minimally invasive transforaminal lumbar interbody fusion. Neurosurg Focus 2006;20:E4

58. Best NM, Sasso RC. Efficacy of translaminar facet screw fixation in circumferential interbody fusions as compared to pedicle screw fixation. J Spinal Disord Tech 2006;19:98-103.

59. Shen FH, Samartzis D, Khanna AJ, Anderson DG. Minimally invasive techniques for lumbar interbody fusions. Orthop Clin North Am 2007;38:373-86.

60. Rodgers WB, Gerber EJ, Patterson J. Intraoperative and early postoperative complications in extreme lateral interbody fusion: an analysis of 600 cases. Spine
(Phila Pa 1976) 2011;36:26-32.

61. Ledet EH, Tymeson MP, Salerno S, Carl AL, Cragg A. Biomechanical evaluation of a novel lumbosacral axial fixation device. J Biomech Eng 2005;127:929-33.

62. Tobler WD, Gerszten PC, Bradley WD, Raley TJ, Nasca RJ, Block JE. Minimally invasive axial presacral L5-S1 interbody fusion: two-year clinical and radiographic outcomes. Spine (Phila Pa 1976) 2011;36:E1296-301.

63. Li X, Zhang Y, Hou Z, Wu T, Ding Z. The relevant anatomy of the approach for axial lumbar interbody fusion. Spine (Phila Pa 1976) 2012;37:266-71.

64. DeVine JG, Gloystein D, Singh N. A novel alternative for removal of the AxiaLif (TranS1) in the setting of pseudarthrosis of L5-S1. Spine J 2009;9:910-5.

65. Johnson WE, Roberts S. 'Rumours of my death may have been greatly exaggerated': a brief review of cell death in human intervertebral disc disease and implications for cell transplantation therapy. Biochem Soc Trans 2007;35:680-2.

66. Tracey I. Imaging pain. Br J Anaesth 2008;101:32-9. 